\title{
FORMULASI KAPA DAN IOTA KARAGENAN DALAM PEMBUATAN PRODUK KOSMETIK PELEMBAP BIBIR
}

\author{
Sujuliyani, Puspa Pebriyanti*, Yuliati H. Sipahutar \\ Prodi Teknologi Pengolahan Hasil Perikanan, Politeknik Ahli Usaha Perikanan Jakarta \\ Jalan AUP No.1 Pasar Minggu, Jakarta Selatan \\ Diterima: 16 Oktober 2020/Disetujui: 3 November 2021 \\ *Korespondensi: pebripuspa12@gmail.com
}

Cara sitasi: Sujuliyani, Pebriyanti P, Sipahutar YH. 2021. Formulasi kapa dan iota karagenan dalam pembuatan produk kosmetik pelembap bibir. Jurnal Pengolahan Hasil Perikanan Indonesia. 24(3): 330-336.

\begin{abstract}
Abstrak
Kapa dan iota karagenan memiliki sifat fungsional sebagai humektan yang dapat mempertahankan kelembapan bibir pada produk kosmetik pelembap bibir (lip balm). Karagenan digunakan sebagai bahan alami yang lebih aman dan mengurangi komposisi bahan kimia dalam formulasi pelembap bibir. Tujuan penelitian ini untuk menentukan formulasi yang terbaik dari kombinasi kapa dan iota karagenan dalam menghasilkan pelembap bibir yang sesuai standar. Perlakuan penambahan kapa dan iota karagenan pada produk pelembap bibir terdiri dari produk tanpa penambahan kapa dan iota karagenan, 1:1, 1:2, 2:1 dan 1:3. Data sensori menggunakan uji Kruskal-Wallis dilanjutkan dengan pembandingan ganda. Parameter mutu yang diuji yaitu $\mathrm{pH}$ dan LoD. Hasil penelitian menunjukkan $\mathrm{pH}$ produk pelembap bibir dengan perlakuan $1: 1,1: 2$, 2:1 dan 1:3 secara berurutan sebesar 5,70; 5,65; 5,55; 5,75 dan pengujian LoD (\%) dengan perlakuan 1:1, 1:2, 2:1 dan 1:3 secara berurutan sebesar 2,09; 1,05; 0,98: 1,01; 0,96. Perbandingan kapa dan iota karagenan terbaik adalah 1:3. Berdasarkan hasil data sensori dan karakteristik mutu, pelembap bibir 1:3 memiliki kenampakan, warna, dan tekstur yang menarik bagi panelis, serta memiliki berat penyusutan yang paling rendah dan mampu menahan kelembapan dalam jangka waktu yang paling lama.
\end{abstract}

Kata kunci: kelembapan, kosmetik alami, susut pengeringan

\section{Formulation of Kappa and Iota Carrageenan in Lip Balm Cosmetic}

\begin{abstract}
Kappa and iota carrageenan have functional properties as humectants that can retain lip moisture in lip balm. As a natural ingredient, carrageenan is safer and reduces the composition of chemicals in lip balm formulations. This research was aimed to determine the best formulation of the combination of kappa and iota carrageenan in producing lip balms. The treatment consist of control without the addition of kappa and iota carrageenan, and the kappa:iota carrageenan of 1:1, 1:2, 2:1, and 1:3. Sensory data using the KruskalWallis test followed by multiple comparisons. The quality parameters tested were $\mathrm{pH}$ and LoD. The $\mathrm{pH}$ of lip balm products with $1: 1,1: 2,2: 1$ and $1: 3$ treatments are $5.70 ; 5.65 ; 5.55 ; 5.75$ respectively and LoD testing (\%) with $1: 1,1: 2,2: 1$ and $1: 3$ treatment are $2.09 ; 1.05 ; 0.98 ; 1.01 ; 0.96$ respectively. The best ratio of kappa and iota carrageenan is $1: 3$. From the results of sensory data and quality characteristics, the 1:3 kappa iota carrageenan lip balm has an attractive appearance, color and texture for panelists, lowest shrinkage weight and retain moisture for the longest period of time among others.
\end{abstract}

Keyword: loss on drying, moisture, natural cosmetic 


\section{PENDAHULUAN}

Pelembap bibir adalah substansi lilin yang dioleskan pada bibir. Pelembap bibir berfungsi untuk melembapkan bibir agar tidak mudah kering dan pecah-pecah. Pelembap bibir mampu memproteksi bibir pada saat kelembapan udara rendah ataupun suhu yang terlalu dingin sehingga mencegah dari penguapan air pada sel-sel epitel mukosa bibir (Ratih et al. 2014).

Pelembap bibir mengandung lilin lebah atau lilin karnauba, kapur barus, setil alkohol, lanolin, parafin, petrolatum, dan bahan-bahan lainnya. Pelembap bibir adalah sediaan kosmetik yang berbasis sama bahan pembuatannya seperti lipstik, tetapi tidak berwarna dan transparan (Ratih et al. 2014). Kosmetik yang berbahan alami dinilai lebih aman karena terbukti dapat menjaga dan meningkatkan kecantikan secara alami (Armin et al. 2013). Pembuatan kosmetik dari bahan alami lebih baik dibandingakan dengan kosmetik yang berbahan sintetis karena bahan sintetis dapat menimbulkan efek samping dan merusak bentuk alami dari kulit (Purnomo 2018). Pada penelitian ini sediaan karagenan dipilih sebagai bahan utama pembuatan pelembap bibir karena secara ekonomi sediaan karagenan cenderung lebih murah, mudah diaplikasikan, aman, dan ramah lingkungan (Hutahuruk 2018).

Karagenan adalah olahan lanjutan dari alkali treated cottonii (ATC) atau semi refined carrageenan (SRC). Tingkat kemurnian SRC lebih rendah dari refined carrageenan karena kandungan sulfatnya masih tinggi, sehingga daya pembentukan gelnya rendah (Anggadiredja et al. 2008). Adapun jenisjenis karagenan berdasarkan sumber bahan baku dan gugus fungsional dapat dibagi menjadi kapa, iota, dan lambda karagenan. Kapa karagenan dihasilkan dari rumput laut Eucheuma cottonii, iota karagenan dari Eucheuma spinosum, dan lambda karagenan dari Chondrus crispus (Herawati 2018).

Karagenan mengandung humektan yang berperan pada kosmetik untuk membentuk film pada lapisan sehingga dapat mempertahankan kelembutan dan kelembapan (Riger 2000). Fungsi humektan tersebut dapat menggantikan fungsi setil alkohol pada kosmetik yang pada umumnya digunakan dalam bahan kosmetik. Penggunaan karagenan sebagai bahan alami dapat mengurangi komposisi bahan kimia dalam formulasi (Hutahuruk 2018). Pada penelitian ini digunakan karagenan jenis kapa dan iota sebagai bahan pembuatan pelembap bibir. Kapa karagenan memiliki kemampuan membentuk gel yang tinggi tetapi memiliki kecenderungan untuk mengalami sineresis, sedangkan iota karagenan memiliki kemampuan pembentukan gel yang lemah (Darmawan et al. 2013). Percampuran kapa dan iota karagenan yang sesuai untuk sediaan pelembap bibir belum diketahui, sehingga perlu dilakukan penelitian tentang formulasi dan karakteristik pada kombinasi kapa dan iota karagenan dalam menghasilkan pelembap bibir yang sesuai standar.

\section{BAHAN DAN METODE Bahan dan Alat}

Bahan utama yang dipakai pada penelitian ini antara lain rumput laut kering E. cottonii dan E. spinosum. Bahan yang digunakan untuk proses pembuatan karagenan yaitu kalium hidroksida (KOH) (Merck), natrium hidroksida $(\mathrm{NaOH})$ (Merck), kalium klorida ( $\mathrm{KCl}$ ) (Merck), isopropil alkohol (Merck), akuades. Bahan yang digunakan untuk proses pembuatan pelembap bibir yaitu cocoa butter (Decotatoo), minyak kelapa (Virgin Bali Coconut Oil), emulgade (SE-PF), lilin lebah murni, metil paraben dan pewangi. Peralatan yang digunakan antara lain penangas air (Memmert), gelas piala (Pyrex), kain belacu, pan stainless steel, blender (Miyako), bak pencucian, spatula, oven (Heraeus instrument), timbangan digital (Kobe), pH meter (Disuu pH meter), cawan tembikar (Duran), alat penjepit, kertas saring, lempeng hangat (hot plate) dan erlenmeyer (Pyrex).

\section{Metode \\ Proses pembuatan karagenan}

Penelitian terdiri dari dua tahap pelaksanaan yaitu proses pembuatan kapa dan iota karagenan serta proses pembuatan pelembap bibir. Prosedur dalam pembuatan kapa karagenan dari rumput laut kering 
E.cottonii mengikuti prosedur berdasarkan SNI 8391-1:2017 karagenan murni dengan persentase larutan $\mathrm{KOH}$ yang sesuai dengan prosedur Hakim et al. (2011)serta pembuatan iota karagenan dari rumput laut kering E.spinosum mengikuti prosedur Darmawan et al. (2014) dengan perubahan persentase larutan $\mathrm{NaOH}$ yang berbeda. Proses pembuatan karagenan diawali dengan menimbang bahan baku lalu pencucian. Setelah itu, rumput laut E.cottonii direbus dengan larutan $\mathrm{KOH} 8 \%$ bersuhu 70-80 ${ }^{\circ} \mathrm{C}$ sedangkan rumput laut E.spinosum menggunakan larutan $\mathrm{NaOH} 8 \%$ bersuhu 50 $60{ }^{\circ} \mathrm{C}$. Masing-masing direbus selama dua jam di dalam penangas air. Volume larutan $\mathrm{KOH}$ dan $\mathrm{NaOH}$ yang digunakan sebagai media perebus sebanyak dua kali berat rumput laut kering. Setelah itu, dilakukan pencucian kembali untuk menghilangkan larutan $\mathrm{KOH}$ $8 \%$ dan $\mathrm{NaOH} 8 \%$ yang masih menempel pada rumput laut. Tahap selanjutnya adalah ekstraksi menggunakan air. Volume air yang digunakan sebanyak sepuluh kali berat rumput laut. Ekstraksi ini berlangsung selama 2 jam dengan suhu $80-90{ }^{\circ} \mathrm{C}$ untuk rumput laut E.cottonii dan suhu $60-70{ }^{\circ} \mathrm{C}$ untuk rumput laut E.spinosum. Selanjutnya proses penyaringan dilakukan dengan kain belacu. Proses penyaringan dilakukan dengan cepat dan masih dalam keadaan panas agar rumput laut tidak membentuk gel. Lalu proses pembentukan gel, rumput laut E. cottonii menggunakan larutan $\mathrm{KCl} 1 \%$ sedangka untuk rumput laut E. spinosum dengan cara menambahkan isopropil alkohol ke dalam wadah yang berisi filtrat dengan perbandingan volume isopropil alkohol pada berat filtrat yaitu 1:2, kemudian diaduk selama 15 menit dan dibiarkan selama 15-30 menit sampai filtrat berubah menjadi serat karagenan. Kemudian dilakukan penyaringan kembali menggunakan saringan kecil. Setelah itu karagenan dikeringkan menggunakan oven bersuhu $40-45^{\circ} \mathrm{C}$ selama 1-2 hari. Karagenan yang sudah kering dihancurkan dengan blender.

\section{Proses pembuatan pelembap bibir}

Proses pembuatan sediaan pelembap bibir terbagi menjadi dua fase yaitu fase minyak dan fase air. Fase minyak meliputi bahan-bahan yang larut dalam minyak di antaranya emulgade, cocoa butter, lilin lebah, dan minyak kelapa. Bahan-bahan yang larut dalam air meliputi air dan karagenan. Adapun perbandingan perlakuan antara kapa dan iota karagenan yaitu $1: 1 ; 1: 2 ; 2: 1$, dan 1:3. Bahan tambahan yang digunakan adalah metil paraben dan pewangi. Semua bahanbahan dasar pelembap bibir yang digunakan ditimbang lalu bahan-bahan yang larut dalam minyak dicampur dan dipanaskan mencapai suhu $70-75{ }^{\circ} \mathrm{C}$. Pada saat yang bersamaan bahan-bahan yang larut air juga dipanaskan hingga mencapai suhu $70-75^{\circ} \mathrm{C}$. Pencampuran bahan pada suhu $60-65^{\circ} \mathrm{C}$ tersebut kemudian didiamkan hingga suhu $45-50{ }^{\circ} \mathrm{C}$ sambil tetap diaduk, kemudian dicampur hingga homogen dan ditambahkan metil paraben dan pewangi. Sediaan pelembap bibir yang dihasilkan disimpan dalam wadah. Formulasi bahan yang digunakan pada saat pembuatan pelembap bibir dapat dilihat pada Table 1 .

\section{Analisis sensori}

Uji Kruskal-Wallis menggunakan perangkat lunak SPSS dilakukan untuk menentukan produk pelembap bibir dengan penambahan karagenan terbaik berdasarkan uji sensori. Uji sensori mengacu pada BSN (1996). Uji sensori dilakukan menggunakan penilaian dengan skala hedonikyang ditransfer dalam bentuk angka. Pengujian ini bersifat subjektif dan menggunakan skala hedonik dengan panelis semi terlatih dari taruna/i Politeknik Ahli Usaha Perikanan berjumlah 30 orang. Uji sensori pada penelitian ini bertujuan untuk mengevaluasi daya terima atau tingkat kesukaan panelis terhadap produk pelembap bibir yang dihasilkan (Carpenter et al. 2000). Parameter yang diamati yaitu kenampakan, warna, aroma, tekstur, dan kelembapan. Pengamatan dilakukan dengan skala hedonik yang bernilai satu sampai lima: (1) sangat tidak suka; (2) tidak suka; (3) netral; (4) suka; (5) sangat suka.

\section{Analisis kimia}

Analisis kimia terdiri dari pengujian $\mathrm{pH}$ pada produk pelembap bibir. Pengukuran $\mathrm{pH}$ mengacu pada BSN (1996). Standar mutu pH 
Table 1 Formulation of lip balm

\begin{tabular}{|c|c|c|c|c|c|}
\hline \multirow{2}{*}{ Ingredients } & \multicolumn{5}{|c|}{ Formulation } \\
\hline & A & B & $\mathrm{C}$ & $\mathrm{D}$ & $\mathrm{E}$ \\
\hline $\begin{array}{l}\text { Ratio of kappa and iota } \\
\text { carrageenan }\end{array}$ & $\begin{array}{l}\text { Without } \\
\text { carrageenan }\end{array}$ & $1: 1$ & $1: 2$ & $2: 1$ & $1: 3$ \\
\hline \multicolumn{6}{|l|}{ Oil phase } \\
\hline Emulgade (g) & 3.00 & 3.00 & 3.00 & 3.00 & 3.00 \\
\hline Beeswax (g) & 20.00 & 20.00 & 20.00 & 20.00 & 20.00 \\
\hline Cocoa butter (g) & 25.00 & 25.00 & 25.00 & 25.00 & 25.00 \\
\hline${ }^{*}$ Coconut oil (g) & 25.00 & 25.00 & 25.00 & 25.00 & 25.00 \\
\hline \multicolumn{6}{|l|}{ Water phase } \\
\hline Aquadest & $\begin{array}{l}\text { Added up } \\
\text { to } 45 \mathrm{~g}\end{array}$ & $\begin{array}{l}\text { Added up } \\
\text { to } 45 \mathrm{~g}\end{array}$ & $\begin{array}{l}\text { Added up to } \\
45 \mathrm{~g}\end{array}$ & $\begin{array}{l}\text { Added up to } \\
45 \mathrm{~g}\end{array}$ & $\begin{array}{l}\text { Added up } \\
\text { to } 45 \mathrm{~g}\end{array}$ \\
\hline ^Kappa carrageenan & - & 1.50 & 1.00 & 2.00 & 0.75 \\
\hline${ }^{\star}$ Iota carrageenan & - & 1.50 & 2.00 & 1.00 & 2.25 \\
\hline \multicolumn{6}{|l|}{ Additional Ingredients } \\
\hline Metil paraben (g) & 0.25 & 0.25 & 0.25 & 0.25 & 0.25 \\
\hline Fragrance water $(\mathrm{mL})$ & 0.50 & 0.50 & 0.50 & 0.50 & 0.50 \\
\hline
\end{tabular}

${ }^{*}$ Modification from Fransiska (2017)

yaitu 4,5-8,0. Pengukuran $\mathrm{pH}$ dari formula yang dibuat menggunakan alat $\mathrm{pH}$ meter. Alat terlebih dahulu dikalibrasi menggunakan larutan dapar standar netral $(\mathrm{pH} 7,01)$ dan larutan dapar asam ( $\mathrm{pH} 4,01)$ hingga alat menunjukkan harga $\mathrm{pH}$ tersebut. Kemudian elektroda dicuci dengan akuades, lalu dikeringkan dengan tisu. Sampel dibuat dalam konsentrasi $1 \%$ yaitu ditimbang $1 \mathrm{~g}$ sediaan dan dilarutkan dalam $100 \mathrm{~mL}$ akuades, lalu dipanaskan. Setelah suhu larutan normal, elektroda dicelupkan dalam larutan tersebut. Alat dibiarkan menunjukkan harga $\mathrm{pH}$ sampai konstan. Angka yang ditunjukkan $\mathrm{pH}$ meter merupakan $\mathrm{pH}$ sediaan (Linda 2012).

Pengujian susut pengeringan/loss on drying (LoD) mengacu pada Ileleji et al. (2010) dengan cara cawan tembikar ditimbang dan dicatat bobot kosongnya. Sampel pelembap bibir ditimbang ke dalam cawan petri. Uji LoD dilakukan dengan cara mengoven sampel kering pada suhu $105{ }^{\circ} \mathrm{C}$ selama dua jam, kemudian cawan dikeluarkan dan disimpan dalam desikator. Persentase LoD dihitung dengan rumus :

$\operatorname{LoD}(\%)=\frac{\text { bobot sampel awal-bobot sampel akhir }}{\text { bobot awal }} \times 100 \%$

\section{HASIL DAN PEMBAHASAN}

Karakteristik Sensori Pelembap Bibir

Waysima et al. (2010) menyatakan bahwa uji organoleptik atau evaluasi sensoris merupakan suatu kegiatan mengukur dan menganalisis karakteristik suatu bahan produk menggunakan alat indera manusia itu sendiri sebagai bentuk penilaian terhadap produk yang dipilih. Hasil uji sensori terdapat pada Table 2.

Table 2 menunjukkan nilai kenampakan paling tinggi diperoleh dengan perlakuan penambahan kapa dan iota 1:3 sedangkan nilai terendah diperoleh dengan perlakuan tanpa penambahan kapa dan iota karagenan. Hasil menunjukkan terdapat perbedaan signifikan pada penambahan perlakuan kapa dan iota karagenan pada produk pelembap bibir $(p<0,05)$. Tingkat kesukaan panelis juga memengaruhi homogenitas dan warna pelembap bibir yang dihasilkan (Fransiska 2017).

Nilai warna paling tinggi diperoleh dengan perlakuan penambahan kapa dan iota 1:3 sedangkan nilai terendah diperoleh dengan perlakuan tanpa penambahan kapa dan iota karagenan. Terdapat perbedaan yang 
Table 2 Sensory result of lip balm

\begin{tabular}{lccccc}
\hline \multirow{2}{*}{ Treatment } & \multicolumn{5}{c}{ Parameter } \\
\cline { 2 - 6 } & Appearance & Color & Aroma & Texture & Humidity \\
\hline Without carrageenan & $2.86 \pm 0.15^{\mathrm{a}}$ & $2.70 \pm 0.14^{\mathrm{a}}$ & $3.42 \pm 0.12^{\mathrm{ab}}$ & $2.55 \pm 0.16^{\mathrm{a}}$ & $3.58 \pm 0.16^{\mathrm{a}}$ \\
$(1: 1)$ & $2.97 \pm 0.09^{\mathrm{a}}$ & $2.95 \pm 0.12^{\mathrm{a}}$ & $3.46 \pm 0.09^{\mathrm{ab}}$ & $2.89 \pm 0.14^{\mathrm{a}}$ & $3.94 \pm 0.12^{\mathrm{ab}}$ \\
$(1: 2)$ & $2.92 \pm 0.11^{\mathrm{a}}$ & $2.90 \pm 0.11^{\mathrm{a}}$ & $3.53 \pm 0.12^{\mathrm{ab}}$ & $3.30 \pm 0.10^{\mathrm{ab}}$ & $3.86 \pm 0.12^{\mathrm{ab}}$ \\
$(2: 1)$ & $3.45 \pm 0.09^{\mathrm{ab}}$ & $3.65 \pm 0.12^{\mathrm{ab}}$ & $3.66 \pm 0.11^{\mathrm{ab}}$ & $3.65 \pm 0.11^{\mathrm{ab}}$ & $4.08 \pm 0.12^{\mathrm{b}}$ \\
$(1: 3)$ & $3.82 \pm 0.14^{\mathrm{b}}$ & $3.95 \pm 0.14^{\mathrm{b}}$ & $3.64 \pm 0.14^{\mathrm{ab}}$ & $3.80 \pm 0.11^{\mathrm{b}}$ & $4.13 \pm 0.09^{\mathrm{b}}$ \\
\hline
\end{tabular}

signifikan pada penambahan perlakuan kapa dan iota karagenan pada warna pelembap bibir $(p<0,05)$. Pelembap bibir dengan perlakuan kapa dan karagenan 1:3 menghasilkan warna lebih putih sedangkan pelembap bibir tanpa kappa dan iota karagenan berwarna agak krim kekuningan. Hal tersebut menyebabkan perbedaan warna memengaruhi tingkat kesukaan panelis (Hutahuruk 2018).

Nilai aroma yang diperoleh dari beberapa perlakuan lainnya hampir sama pada tiap perlakuan, sehingga menunjukkan tidak ada perbedaan yang signifikan dalam penambahan perlakuan kapa dan iota karagenan pada produk pelembap bibir $(p<0,05)$. Hal tersebut terjadi karena formulasi pewangi yang ditambahkan pada setiap perlakuan sama sehingga tidak ada perbedaan dari setiap perlakuan. Tujuan ditambahkan pewangi agar dapat menutupi bau karagenan yang khas dan bahan-bahan penyusun produk (Fransiska 2017).

Nilai tekstur paling tinggi diperoleh dengan perlakuan penambahan kapa dan iota 1:3 sedangkan nilai terendah diperoleh dengan perlakuan tanpa penambahan kapa dan iota karagenan. Terdapat perbedaan yang signifikan dalam penambahan perlakuan kapa dan iota karagenan pada produk pelembap bibir $(p<0,05)$. Velde et al. (2002) menyatakan bahwa karagenan dapat membentukgel secara thermoreversible yang dimanfaatkan sebagai pengental, bahan penstabil dan pembentuk gel dalam bidang industri farmasi, tekstil dan pangan.

Nilai kelembapan paling tinggi diperoleh dengan perlakuan penambahan kapa dan iota 1:3 sedangkan nilai terendah diperoleh dengan perlakuan tanpa penambahan kapa dan iota karagenan. Hasil menunjukkan bahwa ada perbedaan yang signifikan dalam penambahan perlakuan kapa dan iota karagenan pada produk pelembap bibir $(\mathrm{p}<0,05)$. Karagenan yang terkandung dalam rumput laut E.cottonii dan E. spinossum dapat mengikat air sehingga dapat mempertahankan kelembapan. Penambahan kapa dan iota karagenan menghasilkan kesan lembap yang ditimbulkan dan lebih terasa setelah pemakaian pelembap bibir. Karagenan mengandung humektan yang dapat menjaga dan merawat kelembapan kulit (Purwaningsih et al. 2014). Alginat atau karagenan dapat memperbaiki daya retensi air produk pelembab kulit (Wibowo 2014).

\section{Nilai $\mathrm{pH}$}

Derajat keasaman (pH) merupakan parameter penting pada produk kosmetik yang dapat memengaruhi tingkat daya absorpsi pada kulit serta $\mathrm{pH}$ mengukur tingkat keasaman suatu larutan (Untari dan Robiyanto 2018). Produk kosmetik yang memiliki nilai $\mathrm{pH}$ terlalu rendah akan menyebabkan kulit teriritasi dan jika nilai $\mathrm{pH}$ terlalu tinggi akan menyebabkan kulit menjadi kering (Fransiska 2017). Hasil pH disajikan pada Figure 1.

Nilai $\mathrm{pH}$ tertinggi terdapat pada pelembap bibir dengan perlakuan 1:3 yaitu 5,75 sedangkan nilai $\mathrm{pH}$ terendah pada pelembap bibir tanpa penambahan karagenan yaitu 5,00. Nilai $\mathrm{pH}$ masih berada dalam kisaran yang diisyaratkan oleh SNI 16-43991996 yaitu antara 4,5-8,0. Hasil penelitian Nazato et al. (2012) memperlihatkan nilai $\mathrm{pH}$ pada lip gloss atau pelembap bibir sebesar 5,5. Rowe et al. (2009) menyatakan bahwa komposisi pelembap bibir yang tidak menggunakan bahan trietanolamin (TEA) akan memiliki $\mathrm{pH}$ yang bersifat asam, karena bahan TEA bersifat basa dengan nilai $\mathrm{pH}$ 10,5. Nilai $\mathrm{pH}$ akan semakin meningkat apabila penambahan konsentrasi kapa dan 


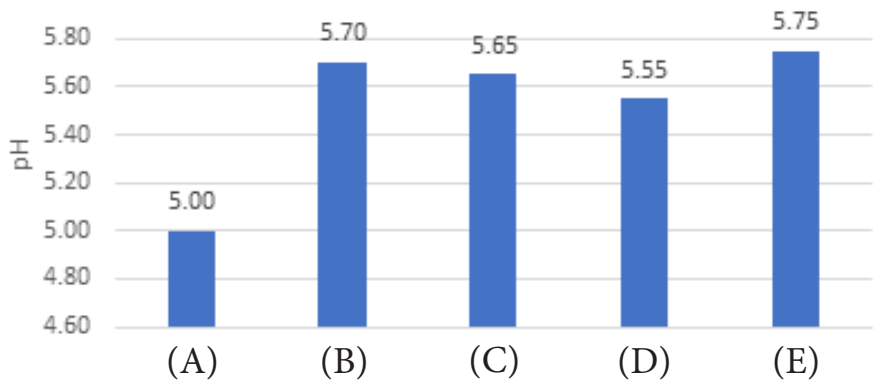

Figure $1 \mathrm{pH}$ value of lip balm with different kappa and iota carrageenan enrichment; (A) without carrageenan; (B) $1: 1$; (C) 1:2; (D) 2:1; (E) $1: 3$.

iota karagenan semakin tinggi. Kapa dan iota karagenan memiliki sifat basa (nilai $\mathrm{pH} 8-9$ ). Proses pembuatan kappa dan iota karagenan terdapat reaksi yang melibatkan gugus $\mathrm{OH}$ sehingga pH karagenan memberikan pengaruh pada $\mathrm{pH}$ pelembap bibir (Hutahuruk 2018).

\section{Susut Pengeringan/Loss on Drying (LoD)}

Pengukuran (LoD dilakukan untuk mengetahui kemampuan pelembap bibir dalam mengurangi penguapan air atau mempertahankan kelembapan. Pengukuran LoD dilakukan dengan akselerasi suhu dan waktu pengujian terhadap suhu dan waktu normal. Akselerasi yang dilakukan yaitu sebesar 4 kali lipat dari suhu ruang. Hasil LoD disajikan pada Figure 2.

Nilai LoD tertinggi terdapat pada pelembap bibir tanpa penambahan kapa dan iota karagenan yaitu 2,09\% sedangkan nilai LoD terendah pada pelembap bibir dengan penambahan perbandingan 1:3 kapa dan iota karagenan yaitu $0,96 \%$. Nilai LoD masih memenuhi standar SNI 16-4399-1996 yaitu berkisar antara 0,95-1,05\%. Hasil penelitian menunjukkan bahwa semakin rendah berat penyusutan setelah pemanasan, bahan mampu menahan kelembapan lebih lama dan dapat berfungsi sebagai pelembap. Pelembap bibir dengan penambahan kapa dan iota karagenan berkurang berat penyusutannya karena pada rumput laut E. cottonii dan E. spinosum memiliki hidrokarbon dalam bentuk karagenan. Karagenan memiliki fungsi sebagai humektan yang dapat mempertahankan kelembapan (Hutahuruk 2018).

\section{KESIMPULAN}

Sifat dan gugus fungsional pada kapa dan iota karagenan yang berbeda tidak berpengaruh signifikan pada pelembap bibir tetapi keduanya memiliki fungsi yang sama sebagai humektan yang mampu menahan kelembapan. Berdasarkan hasil pengujian sensori dan karakteristik mutu pelembap bibir yang terpilih pada penambahan kapa dan iota karagenan 1:3 memiliki kenampakan, warna, dan tekstur yang menarik bagi panelis serta memiliki berat penyusutan yang paling rendah sehingga mampu menahan kelembapan dalam jangka waktu yang lama.

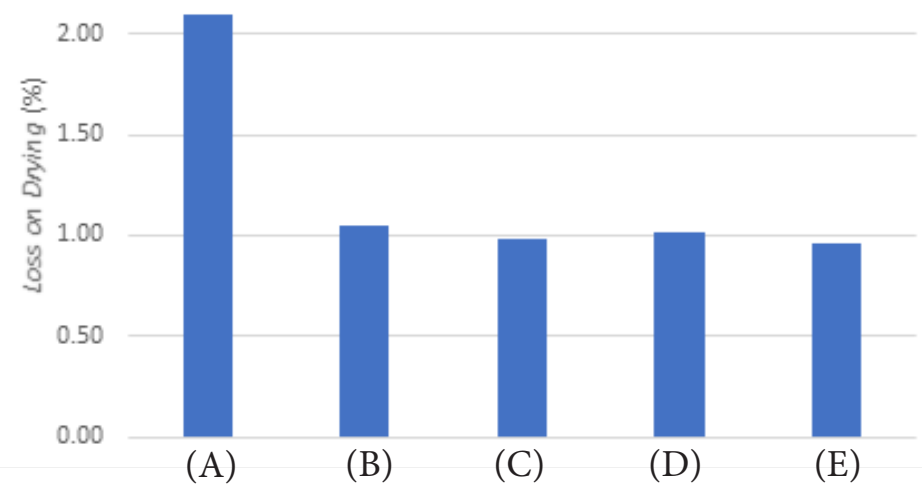

Figure 1 LoD value of lip balm with different kappa and iota carrageenan enrichment; (A) without carrageenan; (B) 1:1; (C) 1:2; (D) 2:1; (E) 1:3. 


\section{DAFTAR PUSTAKA}

Anggadiredja J, Zatnika A, Purwanto H. 2008. Rumput laut: Pembudidayaan, Pengolahan dan Pemasaran Komoditas Perikanan Potensial. Jakarta (ID): Penebar Swadaya.

Angka SL, Suhartono MT. 2000. Bioteknologi Hasil Laut. Bogor (ID): Pusat Kajian Pesisir dan Lautan, Institut Pertanian Bogor.

Armin F, Zulharmita, Firda DR. 2013. Identifikasi dan penetapan kadar merkuri $(\mathrm{Hg})$ dalam krim pemutih kosmetika herbal menggunakan spektrofotometri serapan atom (SSA). Jurnal Sains dan Teknologi Farmasi. 18(1): 28-34.

Carpenter RP, Lyon DH, H. T. 2000. Guidelines for sensory analysis in food product development and quality control. Edisi Kedua. Marylands (US): Aspen.

Darmawan M, Peranginangin R, Sinurat E. 2013. Memproduksi Karaginan dari Rumput Laut. Jakarta (ID): Penebar Swadaya.

Darmawan M, Peranginangin R, Syarief R, Kusumaningrum I, Fransiska D. 2014. Pengaruh penambahan karaginan untuk formulasi tepung puding instan. Jurnal Pascapanen Dan Bioteknologi Kelautan Dan Perikanan. 9(1): 83-95.

Fransiska L. 2017. Formulasi bubur rumput laut Turbinaria sp. dan Eucheuma cottonii sebagai sediaan kosmetik alami lip balm. [Skripsi]. Bogor (ID): Fakultas Perikanan Dan Ilmu Kelautan Institut Pertanian Bogor.

Hakim AR, Wibowo S, Arfini F, Peranginangin R. 2011. Pengaruh perbandingan air pengekstrak, suhu presipitasi, dan konsentrasi kalium klorida (kcl) terhadap mutu karaginan. Jurnal Pascapanen dan Bioteknologi Kelautan dan Perikanan. 6(1): 1-11.

Herawati H. 2018. Potensi hidrokoloid sebagai bahan tambahan pada produk pangan dan nonpangan bermutu. Jurnal Penelitian Dan Pengembangan Pertanian. 37(1): 17-25.

Hestiarty R, Hatryana T, Cahaya PR. 2014. Formulasi sediaan lip balm minyak bunga kenanga (Cananga Oil) sebagai emolien. [Skripsi]. Bandung (ID): Universitas Jenderal Ahmad Yani.

Hutahuruk ENR. 2018. Pengaruh konsentrasi Semi Refined Carrageenan (Eucheuma cottoni) pada pembuatan Skin Lotion. [Skripsi]. Jakarta (ID): Sekolah Tinggi Perikanan.

Ileleji KE, Gracia AA, Kingsly ARP. 2010. Comparison of standard moisture loss on drying methods for determination of moisture content of corn distillers dried grainds with solubles. Journal of Association of Official Analytical International. 93(3): 825-831.

Linda. 2012. Formulasi sediaan lipstik menggunakan ekstrak engkak (Monascus purpureus) sebagai pewarna. [Skripsi]. Medan (ID): Fakultas Farmasi Universitas Sumatera Utara.

Luthfiyana N, Nurjanah, Nurilmala M, Anwar E, Hidayat T. 2016. Ratio of seaweed porridge Eucheuma cottonii and Sargassum sp. as a sunscreen cream formula. Jurnal Pengolahan Hasil Perikanan Indonesia. 19(3): 183-195.

Nazato C, Torres NH, Ferraz SCU, Vilca FZ, Silvia DFC, Aguilar CL, Harder MNC. 2012. Employment of wax sugarcane (Saccharum officinarum) in formulation of a lip gloss by simple extraction and bioethanol. American Journal of Biochemistry. 2(5): 89-93.

Purwaningsih S, Salamah E, Budiarti TA. 2014. Formulasi skin lotion dengan penambahan karagenan dan antioksidan alami dari Rhizophora mucronata lamk. Jurnal Akuatika Indonesia. 5(1): 55-62.

Riger M. 2000. Harry's Cosmeticology. Ed Ke8. New York (US): Chemical Publishing Co Inc.

Rowe RC, Paul JS ME. 2009. Handbook of pharmaceutical excipients. Sixth edition. USA: Pharmaceutical Press and American Pharmacists Association.

Untari EK, Robiyanto R. 2018. Uji fisikokimia dan uji iritasi sabun antiseptik kulit daun Aloe vera (L.) Burm. f. Jurnal Jamu Indonesia. 3(2): 55-61. 